\title{
Ruminations on Intermittent Existence
}

Anthony Adrian

ABSTRACT: Can objects exist, cease to exist, and then exist once more? I lay out three ways to think about intermittent existence (IE). The first section is based on intuitions. The second section will show that the intuitions are bolstered by the concept of supervenience. The final section will argue that the strongest way to think about IE, and about supervenience, is in terms of mereology, the theory of parts and wholes.

\section{The Intuitive Appeal}

I take my gun to a gunsmith for cleaning. Because this gunsmith is the best at what he does, he meticulously disassembles every part of the gun to clean. When finished, he reassembles the gun to return to me. This seemingly mundane example is just the kind of thing that gets metaphysicians foaming at the mouth. Some will say that this is a perfectly good example of a thing having a gap in its existence. ${ }^{1}$ Others will say that the gun I receive back from the gunsmith is a different gun because it is not spatiotemporally continuous (STC). ${ }^{2}$ Surely, if STC is the necessary and sufficient condition for identity over time, the firearm that the gunsmith returns to me is a different one.

Likewise, imagine a scenario where you possess a gun and there is a law that prohibits a person without a proper license to travel with an assembled firearm. In order to travel with the gun, she must disassemble

1. See Trenton Merricks, "There Are No Criteria of Identity Over Time," Nous 32.1 (1998): 106-124.

2. For the best formulation of this idea, see Peter van Inwagen, "Plantinga's Replacement Argument," in Alvin Plantinga, ed. Deane-Peter Baker (Cambridge: Cambridge University Press, 2007): 188-200.

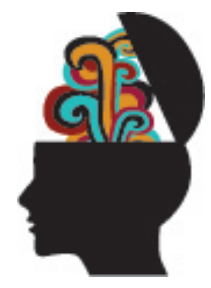




\section{Ruminations on Intermittent Existence}

the firing mechanism for the duration of the trip and reassemble it once she has reached her destination. Upon reaching her destination and reassembling the gun, has she reassembled the same gun?

It would be singularly odd for this traveler to say, "Well I carried my gun to the car this morning, but we are never going to see that thing again. Instead, I have this new gun." Intuitively, it is the very same gun before and after partial disassembly. Perhaps the tension with STC is not apparent because the disassembled parts are within proximity to each other, so instead imagine the gun being disassembled into five different parts and transported in five different cars, each driving five very different, and distant, routes to the same destination at which point the gun is reassembled.

It seems intuitively clear that the gun has intermittent existence. Compare the response to the gun scenario with the following similar examples:

- Our conversation was interrupted, but we resumed it the following week.

- The baseball game was called on account of the rain; it will be made up at a later date.

We would not say that a conversation or a baseball game existed while they were not taking place. Of course it might be challenged that the game and conversation are not material artifacts and so the analogy to the effect that the gun has a period of intermittent existence does not work. The idea is that events (like the baseball game) are just the kind of things that could be paused or interrupted with a period of intermittent existence. Material objects, on the other hand, simply go out of existence and stay out of existence; that is, objects can never come back from going out of existence. However, it is not obvious that the impossibility of intermittent existence is tied to the concept of "material object," just as it is not obvious that the possibility of IE is tied up with the concept of "events." These relationships 
between concepts seem to be discovered from experience. At any rate, it seems clear that at an intuitive level we seem to believe in the idea of intermittent existence.

Though these all seem like fairly innocent intuitive responses, perhaps one may say that the gun never lacked existence. Rather, it existed for a while as a disassembled gun. At this point, intuitions cannot help us any longer since saying that the gun existed as a disassembled firearm is not absurd. The intuitional responses to this thought experiment prove inconclusive and we should seek guidance elsewhere. I find it in supervenience.

\section{The Supervenience Story}

Two paintings will be useful in illustrating supervenience. Suppose that two different paintings have precisely the same microphysical structure. Let us call the microphysical properties the paintings have the A-properties. Now when we ask, "Is one painting more beautiful than the other?" we are asking if the paintings differ in their aesthetic qualities which are macrophysical properties, or B-properties. Supervenience says that two things cannot differ in their B-properties without differing in their A-properties. Since the two paintings have the exact same microphysical structure, their aestheic qualities will be identical. This is the nature of supervenient properties: larger, or macroscopic, qualities supervene on smaller, or microscopic objects arranged in a certain way.

It is easy to see that the B-properties supervene on the A-properties when they are arranged in a certain way. After all, we would hardly expect the two paintings to look exactly the same if they had the same kind of microscopic matter but arranged in a different way. Likewise, we would not say that two guns have the same B-properties such as texture, weight, engravings, etc. if the microscopic A-properties differed.

But, to return to the gun, it is going to be difficult to say that the gun exists as a disassembled gun for some time. (Recall that this is the objec- 


\section{Ruminations on Intermittent Existence}

tion which led us to abandon our intuitional responses in the first place.) Consider a person who has yet to finish assembling her first hand-made gun. When a friend of hers sees her working on this gun and asks, "What have you got there?" it would not be unusual for the woman to reply, "This is my first gun." If this sort of reply were not wrong, it would mean that the B-properties of gunness (like the ones mentioned above, and, namely, the ability to fire a bullet) could supervene on unassembled parts of a gun. What are we to make of this consistency of an unassembled artifact with ordinary language? I am confident that this is just a convention of the English language; the woman does not honestly believe she has a gun in her hands. Rather, it is much more convenient for her to say the she has a gun instead of saying the equally accurate statement, "These are the pieces to my first gun that I have been working on." I say the disassembled gun is not a gun because one of the features of artifacts is that it usually performs some particular sort of function.

An object is a gun if and only if it can function as a firearm. I take the "firing capacity" property to be essential for an object to qualify as a firearm. Note that the object does not have to be firing in order to be a gun. A historically important gun in a museum is not firing, but it does have the capacity to fire a bullet, even if we need to clean some rust off of it, and so it too qualifies as a gun. If an object lacks the capacity to fire a bullet, in what sense are we talking about a gun? Surely an object may resemble a gun, such as in the case of replicas and children's toys. However, people do not drive to a firing range to handle replica guns; they go to a firing range to practice using the gun's main feature, which is, of course, the ability to fire a bullet.

Note that the gun does not necessarily need to be made of a metal material. Plastic or carbon fiber, or gold or platinum, would do just as well if they were assembled to function as a gun. The fact that a gun could be made out of such different materials shows that what is absolutely essential to a gun is not the stuff it is made out of. Rather, the essence of a gun is 
its ability to fire a bullet. Since I am arguing the function of the object is essential to its being a certain object, does a disassembled (or preassembled) gun really have the capacity to function as a firearm? It does when it is assembled, that much is clear, but in a state of disassembly there is nothing about the parts being within proximity to one another that lends the aggregate of gun parts the capacity to function as a firearm.

So my question to someone who holds that "gunness" can supervene on disassembled parts is this: what is it that the "firing capacity" property is supervening on? If a gun (or any other artifact) does supervene on its disassembled (or preassembled parts), when did the supervenience start? Surely there must have been a time when the gun did not exist. After all, the gun has not existed forever. When was it true that the gun did not exist? Perhaps the time when the gun failed to exist is when the smaller parts of the major parts of the gun (for example, the textured grips that are placed on the handle) were being assembled. But why? What is it about the larger, presumably more important, parts simply being close together that entails the existence of the gun?

One could insist that when a gun has been disassembled, the gun has not suddenly gone out of existence, but became a "disassembled gun" because the functional aspect of a gun is not essential to the identity of the object. But the gun and the disassembled gun are plainly not the same object. The gun has an additional property that the disassembled parts do not - the property of firing capability. And if two things do not have the same properties, by Leibniz's Law (The Indiscernibility of Identicals), they cannot be identical. ${ }^{3}$

Ultimately, supervenience will only say something like, "The Bproperties cannot differ without different A-properties." Jaegwon Kim used to think that supervenience could explain the mind-body problem, but now he thinks that supervenience just is the problem stated. ${ }^{4}$ That is to

3. Wilhelm Gottfried Leibniz, Discourse on Metaphysics (1686): section 9.

4. Jaeqwon Kim, Supervenience and Mind, (Cambridge: Cambridge University Press, 1993). 


\section{Ruminations on Intermittent Existence}

say, the fact that psychological properties cannot differ without neurological properties differing is not a solution to the mind-body problem, it is the problem precisely. Why is it that this relation holds? That is the mind-body problem.

Likewise, when we say that a gun supervenes on its assembled parts, this does not amount to a metaphysically deep thesis. This, like the mind/body supervenience example above, is the phenomenon stated, not a solution. Since properties supervene on parts of an object when they are arranged a certain way, we need to closely examine the part-whole relationship.

\section{Mereology}

Mereology is the study of the relationship between parts and wholes. ${ }^{5}$ The notion of "part" is perhaps as familiar as any concept we use in ordinary language: the ham is part of the sandwich; the student is part of the class; this section is part of a paper on intermittent existence. The remainder of this paper will suppose the truth of some of the axioms laid out in classical extensional mereology (CEM) as presented in Leonard and Goodman's Calculus of Individuals. ${ }^{6}$ Among the axioms pertinent to intermittent existence are the universality of composition, extensionality of parthood, and the like. For the sake of conciseness, I will not consider intermittent existence in terms of "alternative" mereologies that take their inspiration from Aristotle and Plato. ${ }^{7}$

Mereology takes the concept "part" as basic and unanalyzable. Parthood is a reflexive, antisymmetric, and transitive relation, as below:

5. For the most comprehensive look at the history and applications of mereology, see Peter Simons, Parts: A Study in Ontology (New York: Oxford University Press, 2000).

6. Henry S. Leonard and Nelson Goodman, "The Calculus of Individuals and Its Uses," The Journal of Symbolic Logic 5.2 (1940): 45-55.

7. See Kathrin Koslicki, The Structure of Objects, (New York: Oxford University Press, 2008) and Verity Harte, Plato on Parts and Wholes: The Metaphysics of Structure, (New York: Oxford University Press, 2005). 


\section{Reflexivity Pxx}

\section{Antisymmetry Pxy $\wedge$ Pyx $\longrightarrow x=y$ \\ Transitivity Pxy $\wedge \mathrm{Pyz} \longrightarrow \mathrm{Pxz}$}

Reflexivity states that anything whatsoever is a part of itself. This relationship is just like the identity relation that says that anything is identical with itself. (But is that the typical notion of parthood? More on that question below.) Antisymmetry states that no two things are parts of each other. For example, a banana is a part of a banana tree but the tree is not a part of the banana. As we can see, antisymmetry tells us that parthood is a one-way street. Lastly, suppose you have a Russian nesting doll. When the doll is opened you discover a slightly smaller doll much like the one just opened. This second doll is part of the first doll. Then, as with all Russian nesting dolls, when you open the second doll you will find yet another smaller doll. This third doll is a part of the second doll, and it is also a part of the first doll, and so on and so forth for subsequent smaller dolls inside the nesting dolls. This is the transitivity of parthood.

One of the main features of classical extensional mereology is that it is extensional. We will need to keep this principle in mind as we progress through this paper. The extensionality of parthood (EP) may be stated as such:

EP If $x$ and $y$ are composite objects with the same proper parts, then $\mathrm{x}=\mathrm{y}$.

Mereological universalism states that any plurality of objects is itself an aggregate or sum. A table, my left earlobe, and President Barak Obama form an aggregate. Mereological universalism entails that, no matter how scattered or gerrymandered the object in question is, as long as the parts exist then the aggregate exists. As such, the aggregate exists only when all the parts exist. If any of the parts cease to exist, then the aggregate is no more; mereological sums cannot survive the loss of a single part. Notice that the 


\section{Ruminations on Intermittent Existence}

functional aspect of the aggregate is not needed, unlike the supervenience theory above.

Now let us return to the objection that the gun exists while disassembled. So the gun does exist while disassembled, says our interlocutor. To see this, note that the parts that compose the sum while disassembled are precisely the same parts that compose the gun after assembly. By extensionality of parthood, the sum of the parts and the gun are identical. Therefore, the same gun exists prior to assembly and after disassembly, and a gun while disassembled and once reassembled is not a case of intermittent existence.

But are the parts really identical with the gun? Here is an argument using Leibniz's Law (Indiscernibility of Identicals) that shows that they are not identical:

1. The sum, or aggregate, of the parts cannot lose any single part.

2. The gun can lose a single part,

3. Therefore, the gun is not a mereological sum

Propositions 1 and 2 describe different persistence conditions, thus, by Leibniz's Law, the gun and the aggregate are not identical. But did we not already concede the truth of EP? Yes, we have. So that means that the gun and the aggregate have the same parts, right? No. To see this we only need to invoke the standard mereological notions of proper and improper parthood:

\section{Proper Parthood $\forall(\mathrm{x}) \forall(\mathrm{y})($ PРxy $\longrightarrow($ Рxy $\neg$ Рух $))$}

Which reads: if $x$ is a proper part of $y$, then $x$ is a part of $y$ and $y$ is not a part of $x$. This concept is sometimes put in terms of overlapping (part sharing). So if $x$ is a proper part of $y$, then all parts of $x$ overlap the parts of $y$ but $y$ has 
at least one part that does not overlap with $x$. Proper parthood, then, is the typical, everyday conception of parthood that is only had by certain things.

Improper parthood is had by every object to itself. Any object, such as a spoon or a banana, is an improper part of itself. And so, the mereological sum of the parts of the gun is an improper part of itself. On the other hand, the mereological sum is a proper part of the gun. Therefore, the sum and the gun do not have the same proper parts. As mentioned above, the mereological sum has its parts essentially - it is not the same sum if even one microphysical particle is missing. Proper parthood allows us to keep the non-identity of a thing and its parts without having to countenance something extra or over and above the parts themselves. ${ }^{8}$

Now we can see where mereology can help with explaining the supervenient relationship of the A-properties and the B-properties of the gun. We may say that the B-properties (the firearm capacity of a gun, the uniform look of it, etc.) cannot be exemplified unless the A-properties (being a mereological sum of the smaller, perhaps microphysical, parts in this case) are in a subvenient relation, and to be in a subvenient relation is to be a proper part of something. As above, to be a proper part of something $x$ is to be a part of an object $y$ and for $y$ not to be a part of $x$.

When the parts of the gun are not assembled, they merely form a mereological sum. The B-properties of a gun cannot supervene as of yet since the sum is not in an arrangement that would yield the parts as proper parts of the gun. Thus, "gunness" itself cannot supervene on the mereological sum of the parts, and, as such, when there is not a gun. So even mereology will not aid with the claim that the gun exists for a while as a disassembled gun. Let us return now to the case where the woman has disassembled her gun for transportation. Once she reaches her destination, she has her disassembled parts and she has her extensionality of parthood

8. This is sure to be controverted by traditional mereologists, but for more on how an artifact could have different proper parts than the mereological sum of its parts, see Achille Varzi, "The Extensionality of Parthood and Composition" Philosophical Quarterly 58.230 (2008) 108-133, especially pages $119-122$. 


\section{Ruminations on Intermittent Existence}

principle handy. Once reassembled, by EP, she has, once again, the same gun as before disassembly. Note that the reassembled gun has all the same proper parts as before the trip. And if we have the same proper parts, we have ourselves the same object.

Through mereology, we have found a case of intermittent existence. At the beginning of the trip, the woman takes her assembled gun, which is composed of parts P1....Pn, and disassembles it for transportation. During the trip, the disassembled parts do not compose a gun, only a mereological sum. So if the parts fail to compose a gun, a gun is not present while she takes her little trip. As above, once she reaches her destination, she takes the mereological sum and composes the same gun. By EP, she has her same gun back.

To be sure, this is not a conclusive argument. What I have said about the gun and mereology says nothing about mereological change. For instance, EP tells me that at the end of the story, the woman has her same gun that she had at the beginning of the story. But what about when she takes another trip, years later, to a gun shop because her gun needs a new part? The replacement of, say, the firing pin, may be a significant mereological change that would forever destroy the original gun. This would amount to the thesis of mereological essentialism. Artifacts, like sums, have their parts essentially and cannot survive change. This is not a popular thesis among mereologists by any means, though it does have a formidable endorser in Roderick Chisholm. ${ }^{9}$

Given the strength of mereological explanations, an argument for or against intermittent existence will have to address mereological change involving parthood at a time and even whether objects have temporal parts (4-Dimensionalism) or not (3-Dimensionalism). The mereological argument will also need to respond to paradoxes of composition such as the problem of the many. To be sure, the debate is complex. But at least we understand the debate would do well to carry on in mereological terms.

9. See Roderick Chisholm, "Parts as Essential to their Wholes," The Review of Metaphysics 26.4 (1973): 581-603. 